\title{
Remote Sensing of Suspended Sediments and Shallow Coastal Waters
}

\author{
Rong-Rong $\mathrm{Li}^{1,2},{ }^{*}$, Yoram J. Kaufman ${ }^{2}$, Bo-Cai Gao ${ }^{3}$, and Curtiss O. Davis ${ }^{3}$ \\ ${ }^{1}$ Science Systems and Applications, Inc., Lanham, MD \\ ${ }^{2}$ Code 913, NASA/Goddard Space Flight Center, Greenbelt, MD \\ ${ }^{3}$ Remote Sensing Division, Code 7212, Naval Research Laboratory, Washington, DC \\ ${ }^{*}$ Corresponding author address: Rong-Rong Li, Code 913, NASA/GSFC, Greenbelt, MD 20771 \\ E-mail: lirongr@climate.gsfc.nasa.gov
}

\begin{abstract}
Ocean color sensors were designed mainly for remote sensing of chlorophyll concentrations over the clear open oceanic areas (case 1 water) using channels between 0.4 and $0.86 \mu \mathrm{m}$. The Moderate Resolution Imaging Spectroradiometer (MODIS) launched on the NASA Terra and Aqua Spacecrafts is equipped with narrow channels located within a wider wavelength range between 0.4 and $2.5 \mu \mathrm{m}$ for a variety of remote sensing applications. The wide spectral range can provide improved capabilities for remote sensing of the more complex and turbid coastal waters (case 2 water) and for improved atmospheric corrections for ocean scenes. In this article, we describe an empirical algorithm that uses this wide spectral range to identifying areas with suspended sediments in turbid waters and shallow waters with bottom reflections. The algorithm takes advantage of the strong water absorption at wavelengths longer than $1 \mu \mathrm{m}$ that does not allow illumination of sediments in the water or a shallow ocean floor. MODIS data acquired over the east coast of China, west coast of Africa, Arabian Sea, Mississippi Delta, and west coast of Florida are used in this study.
\end{abstract}




\section{Introduction}

Since the launch of the Coastal Zone Color Scanner (CZCS) (Hovis et al., 1980) in 1978 ocean color remote sensing has been focused on the estimation of chlorophyll concentrations over the open oceanic areas (Case 1 water) (Morel and Prieur, 1977) using satellite instruments having 6 to 8 channels in the spectral range between 0.41 and $0.865 \mu \mathrm{m}$ (Gordon et al., 1980; Hooker et al., 1992). The main purpose of such remote sensing studies is to improve our understanding of the carbon cycle and the role of the ocean in climate change. In recent years, the ocean science community becomes more interested in remote sensing of the more complex coastal waters. Approximately $60 \%$ of the human population lives in the coastal zone. Human activities are modifying the patterns of water runoff and the delivery of nutrients and sediments to coastal waters. The MODIS instrument is a multi-purpose instrument with a total of 36 channels for remote sensing of the atmosphere, land surface, and ocean color. In comparison with previous generation of satellite instruments, the MODIS instrument (Salomonson et al., 1989; King et al., 1992) allows improved capabilities for monitoring the more complex and turbid coastal waters (Case 2 water) (Morel and Prieur, 1977). In this paper, we describe a simple yet robust algorithm for identifying coastal waters with large amounts of suspended sediments. Shallow coast waters with significant signals reflected from the bottom are also detected. We present sample results from applications of our algorithm to several MODIS data sets acquired over different geographic regions.

\section{Background}

The impetus to study methods for masking coastal waters was our desire to improve remote sensing of aerosol over the oceans from MODIS (Tanré et al., 1997; 1999; Remer et al., 2002). The aerosol retrieving algorithm uses six MODIS channels centered at $0.55,0.66,0.86,1.24$, 1.64 and $2.1 \mu \mathrm{m}$ to derive aerosol models and aerosol optical depths. In the aerosol algorithm, the water leaving radiance is normalized to reflectance units, and called "water leaving reflectance". It is assumed to be zero in the 0.86-, 1.24-, 1.64-, and 2.13- $\mu \mathrm{m}$ channels. The water leaving reflectances at $0.55-, 0.66-\mu \mathrm{m}$ channels were assumed to be the typical clear water (case 1 ) reflectances. Any unaccounted elevated values of the water leaving reflectance were interpreted as an increase in the optical thickness of the fine aerosol particles. Sediments and shallow waters provided such unaccounted high reflectances and resulted in systematic overestimate of the aerosol optical thickness.

In order to improve our aerosol retrieving algorithm over the ocean, we need to develop a procedure to automatically mask out the turbid water areas. Through studies of apparent reflectance spectra acquired with the Airborne Visible Infrared Imaging Spectrometer (AVIRIS) (Vane et al., 1993) from a NASA ER-2 aircraft at an altitude of $20 \mathrm{~km}$ over very turbid waters and relatively clearer waters, as illustrated in Figure 1, we realized that the main differences between the two types of waters are located in the $0.4-0.7 \mu \mathrm{m}$ spectral range. The turbid water has significantly larger reflectances than the clear water. This formed the basis for the development of our turbid water masking algorithm for MODIS data. 


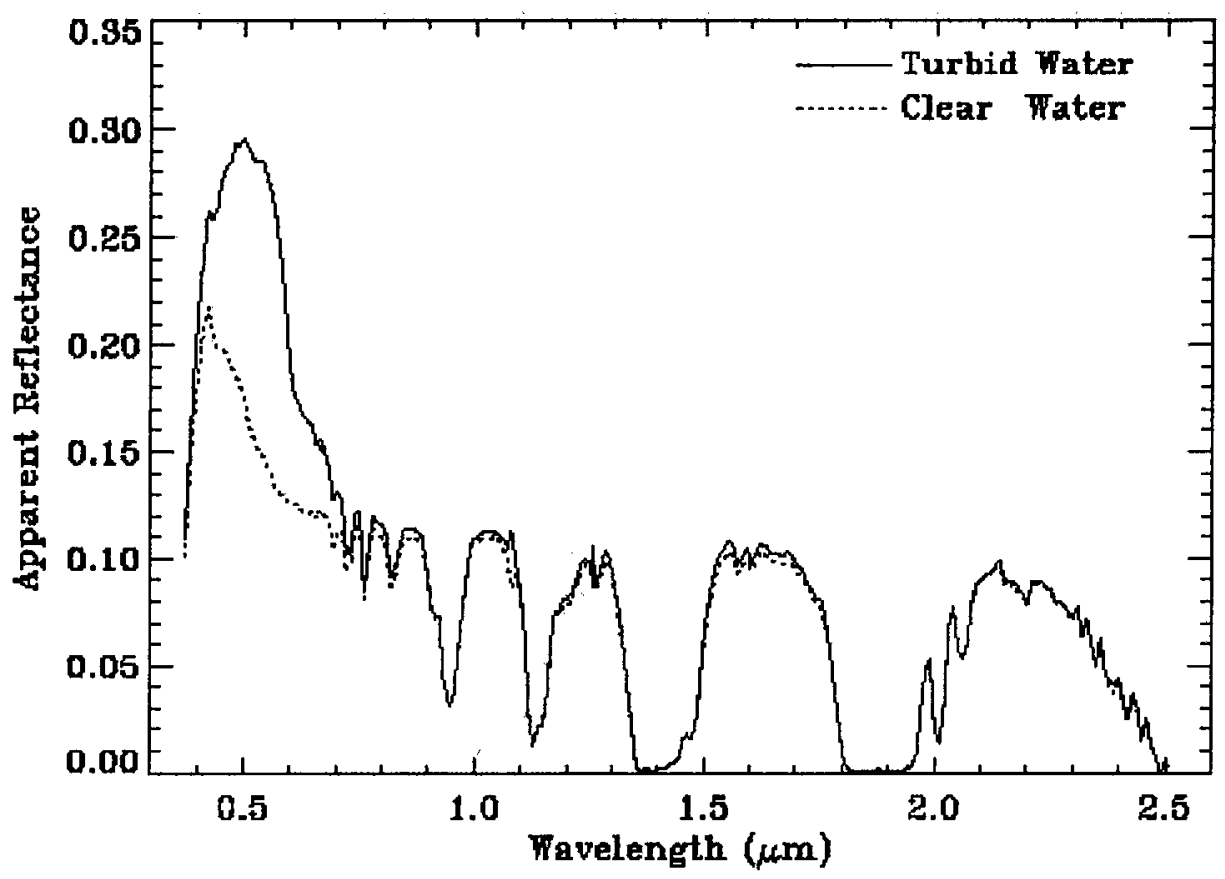

Fig. 1. Examples of apparent reflectance spectra acquired with the Airborne Visible Infrared Imaging Spectrometer (AVIRIS) from a NASA ER-2 aircraft at an altitude of $20 \mathrm{~km}$ over the very turbid water (solid line) and relatively clearer water (dotted line). The AVIRIS data were measured over water surfaces close to the Honolulu Airport in April 2000.

\section{The Algorithm}

The seven MODIS solar channels centered at 0.47, 0.55, 0.66, 0.86, 1.24, 1.64 and 2.13 $\mu \mathrm{m}$ were originally designed for remote sensing of land and cloud properties (King et al., 1992; Justice et al., 1998). We have found that these channels are quite useful for remote sensing of the brighter coastal waters. In this paper, we describe the algorithm development through examples.

Figure 2 shows a color image (red: $0.66 \mu \mathrm{m}$; green: $0.55 \mu \mathrm{m}$; blue: $0.47 \mu \mathrm{m}$ ) processed from the MODIS data acquired over the east coastal areas of China on November 11, 2001. Some of the areas were covered by turbid waters with significant amounts of suspended sediments (yellowish color). Portions of the areas were covered by haze aerosol from urban pollution. We selected 10 small areas, as marked in the figure, for detailed analysis. Based on visual inspection areas 1 to 5 are less turbid and are referred to here as the "clear" water areas. Areas 6 to 10 are visually turbid water areas with suspended sediments. 


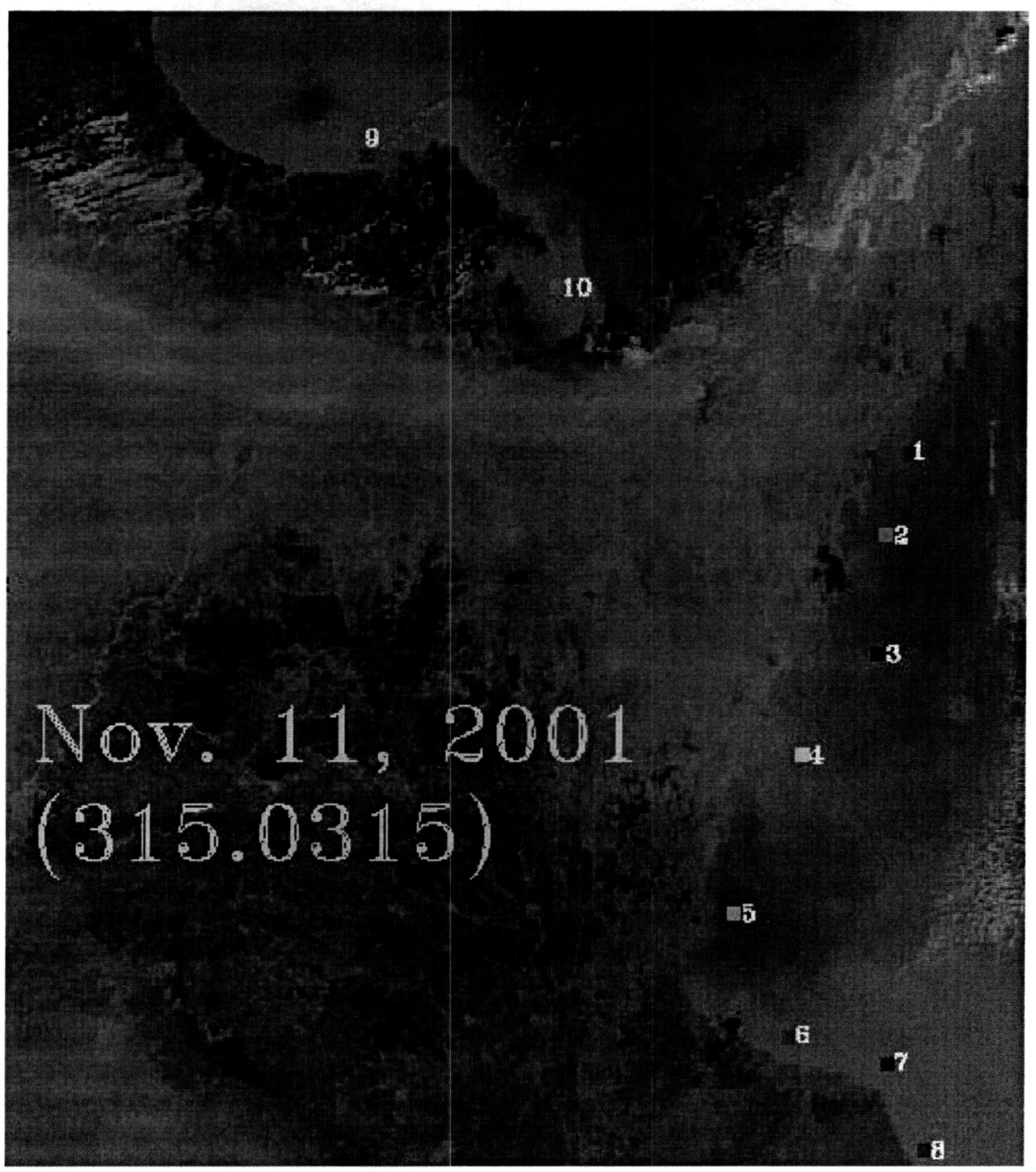

Fig. 2. MODIS image (red: $0.66 \mu \mathrm{m}$; green: $0.55 \mu \mathrm{m}$; blue: $0.47 \mu \mathrm{m}$ ) acquired over the east coastal areas of China on November 11, 2001. The image shows low sediment areas (\#1-5), high sediment areas (\#6-10) and varying amount of pollution aerosol - the gray-brown haze.

The comparisons between the spectral properties of regions with and without sediments are shown in Figure 3. The Fig. 3a shows a plot of the ocean + atmosphere reflectance (termed apparent reflectance) as a function of wavelength for clear water from areas 4 and 5 . Note that area 4 is influenced more by the haze aerosol than area 5. The spectral reflectances from area 4 fit very well with a power law formula, which is illustrated by a straight line on this log-log scale plot. The same is true for the reflectances from target 5, but with lower values and a steeper slope, due to the smaller aerosol concentration. The correlation for both areas 4 and 5 is 0.999 . Figure $3 \mathrm{~b}$ shows a similar plot for the turbid water areas 8 and 9 . A fit was performed using the area 9 data points from the 0.47-, 1.24-, 1.64- and 2.13- $\mu$ m channels. Because the reflectances at 0.55-, 0.66-, $0.86-\mu \mathrm{m}$ channels are affected by the presence of sediments, the data points from these three channels are not included in the fitting. The observed reflectance values of these 3 channels are 
well above the straight line. The excess reflectances are attributed to the back scattering of solar radiation by sediments.

(a)

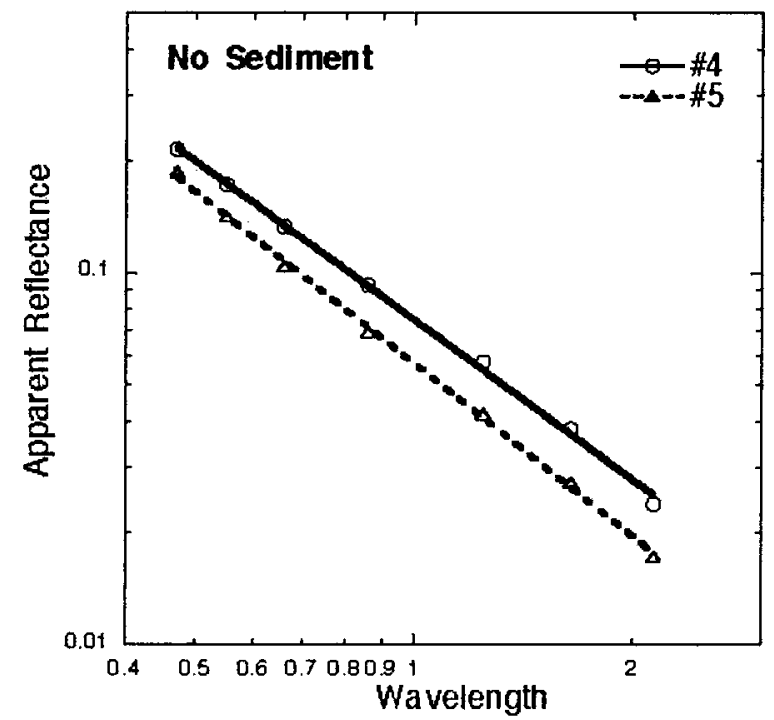

(b)

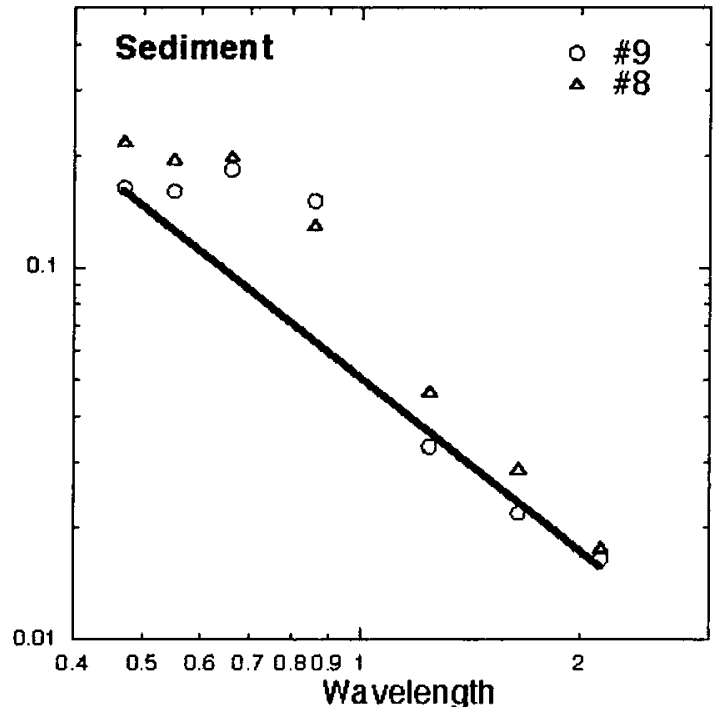

Fig. 3. (a): Plot of the apparent reflectance (reflectance of the ocean + atmosphere) as a function of wavelength for clear water (areas 4 and 5, marked in Fig. 2); and (b): a similar plot but for the turbid water areas 8 and 9 , as marked in Fig. 2. The line in (b) was obtained using the area 9 data points from the 0.47-, 1.24-, 1.64- and 2.13- $\mu \mathrm{m}$ channels.

In order to have more theoretical understanding on the usefulness of the longer MODIS wavelengths to separate sediments from aerosol, we have made calculations of pure liquid water transmittance as a function of wavelength using the liquid water absorption coefficients compiled by Wieliczka et al. (1989). The transparency of pure water to sunlight decreases rapidly with increasing wavelength in the $0.5-2.5 \mu \mathrm{m}$ spectral region. Table 1 lists the penetration depths at the level of $90 \%$ light attenuation. The sunlight at $0.55 \mu \mathrm{m}$ can penetrate about $40 \mathrm{~m}$ under the very clear water surface. Its penetration depth is about $50 \mathrm{~cm}$ at $0.86 \mu \mathrm{m}$, down to $2 \mathrm{~cm}$ at $1.24 \mu \mathrm{m}$, and further down to $1 \mathrm{~mm}$ at $2.13 \mu \mathrm{m}$. Thus, the turbidity in water can affect reflectance in visible channels and even at $0.86 \mu \mathrm{m}$. It is not easy to distinguish sunlight reflected by turbid waters or by aerosols using wavelengths $<1 \mu \mathrm{m}$. However, for the longer wavelengths $(1.2,1.6$ and $2.1 \mu \mathrm{m})$ the penetration depths of sunlight into the water are very small, eliminating the possibility of the reflection by sediments. We found that the blue channel $(0.47 \mu \mathrm{m})$ is very sensitive to atmospheric molecular scattering, but less sensitive to the additional reflection by sediments. For coastal waters, this channel is not nearly as sensitive as the $0.55-\mu \mathrm{m}$ channel to sediment reflection because of strong absorption by dissolved organic matters (yellow substances) at $0.47 \mu \mathrm{m}$. In summary, the MODIS measurements over the ocean at 0.47-, 1.2-, 1.6- and 2.1- $\mu \mathrm{m}$ are influenced mainly by aerosol scattering and absorption and can be used to derive the atmospheric spectral power-law. Measurements at $0.55-0.86 \mu \mathrm{m}$ are influenced both by the aerosol and the sediments. The excess reflectance at $0.55-0.86 \mu \mathrm{m}$ beyond the power-law values can be associated to the presence of sediments and used for their detection. 
Table 1. Light penetration depths at the level of $90 \%$ light attenuation for several wavelengths.

\begin{tabular}{ll}
\hline Wavelength $(\mu \mathrm{m})$ & Penetration Depth $(\mathrm{m})$ \\
\hline 0.55 & 41 \\
0.86 & 0.49 \\
1.24 & 0.02 \\
1.64 & 0.004 \\
2.13 & 0.001 \\
\hline
\end{tabular}

The sediment masking algorithm follows: we first use the apparent MODIS reflectances at $0.47,1.24,1.64$, and $2.13 \mu \mathrm{m}$ to derive the power-law fit illustrated in Fig. 3b. Then we calculate reflectances at $0.55,0.66$, and $0.86 \mu \mathrm{m}$ based on the fitted line. The differences between the satellite measured reflectances of the 0.55-, 0.66-, and 0.86- $\mu \mathrm{m}$ channels and the calculated reflectances for the same channels are the excess reflectance introduced by sediments. Figure 4 shows the reflectance differences for the $0.55-\mu \mathrm{m}$ and $0.66-\mu \mathrm{m}$ channels and for all the 10 selected targets. For the clear water areas, the differences at $0.55 \mu \mathrm{m}$ are close to zero; while for the turbid water areas, the differences are all greater than 0.01 . In this case study, both the $0.55-\mu \mathrm{m}$ channel and the $0.66-\mu \mathrm{m}$ channel can, in principle, be used for sediment detections. Our analysis of MODIS data measured over other geographical regions have shown that the reflectance difference for the $0.55-\mu \mathrm{m}$ channel is also sensitive for detecting shallow waters with bottom reflections. The $0.55-\mu \mathrm{m}$ channel can sense far deeper into the ocean than the $0.66-\mu \mathrm{m}$ channel because of much smaller liquid water absorption at $0.55 \mu \mathrm{m}$ than at $0.66 \mu \mathrm{m}$ (Mobley, 1994). The shallow waters with measurable bottom reflections also need to be masked out for the aerosol retrievals from MODIS data (Tanré et al., 1997). Therefore, we have decided to use the reflectance difference of the $0.55-\mu \mathrm{m}$ channel for sediment masking. The selected threshold value for the reflectance difference is 0.01 .

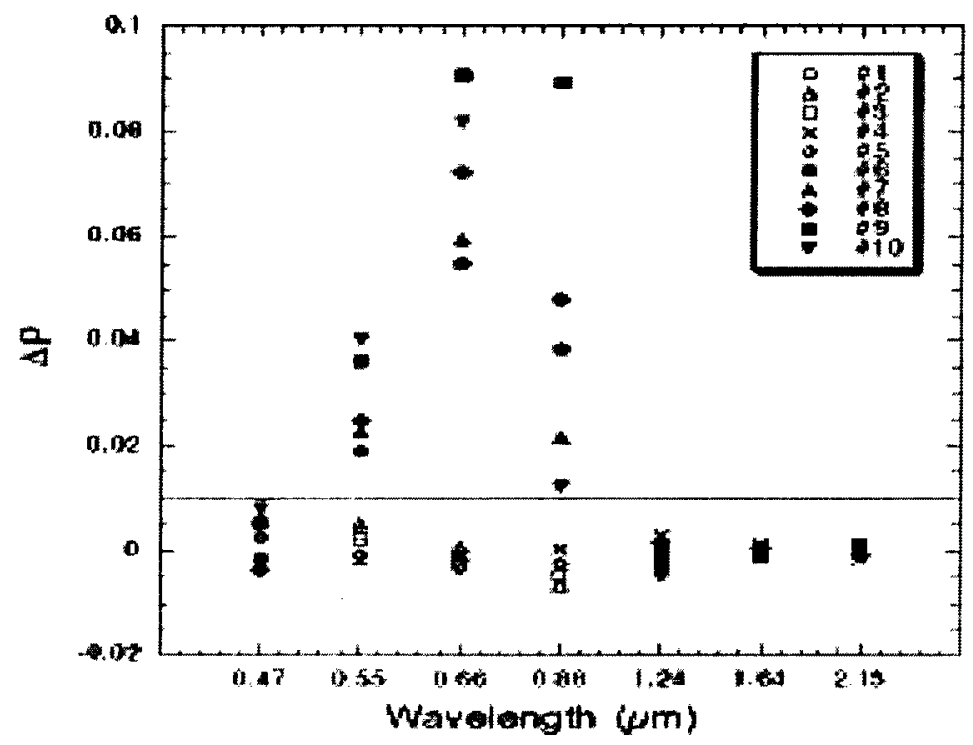

Fig. 4. Reflectance differences for the 0.47-, 0.55- 0.66- and 2.13- $\mu \mathrm{m}$ channels for all the 10 selected targets marked in Fig. 2. The reflectance difference is calculated as the difference between the actual reflectance measured at the top of the atmosphere and the power law interpolated reflectance (linear fit in a $\log x \log$ scale). The line at 0.01 is the threshold value used to identify the pixels with high sediment reflectance for masking. 
In order to develop an empirical algorithm for global applications, we have examined reflectance properties of different types of targets from many MODIS data sets. Figure 5a shows the wavelength dependences of MODIS data measured over clear waters and under different atmospheric conditions, such as those with large amount of haze, light and heavy smoke originated from biomass burning, light and heavy dust. The absolute reflectance values can differ significantly from one area to another area. However, the data points from the 7 MODIS channels for each of the selected areas can be fitted well by a power law (correlation of 97-100\%) except for very heavy dust where the correlation is only $72 \%$. The reason for the good fit is that aerosol scattered light exhibits a power-law dependence to a first degree of approximation. For the aerosol optical thickness it is termed the Angstrom exponent. Second order deviations are found for very heavy concentration of specific aerosol types (e.g. dust, smoke or pollution) [Eck et al., 1991].

Figure $5 \mathrm{~b}$ shows MODIS data acquired over areas with sediments and under varying dust conditions. For each of the selected targets, a straight line is obtained by fitting reflectances only from the 0.47-, 1.24-, 1.64-, and 2.13- $\mu$ m channels. The data points for the measured reflectances of the 0.55-, 0.66-, and 0.86- $\mu \mathrm{m}$ channels are located all above the fitted line. The differences between the measured reflectances for the three channels and those predicted with the straight line result from the scattering of solar radiation by sediments on or below the water surfaces.

(a)

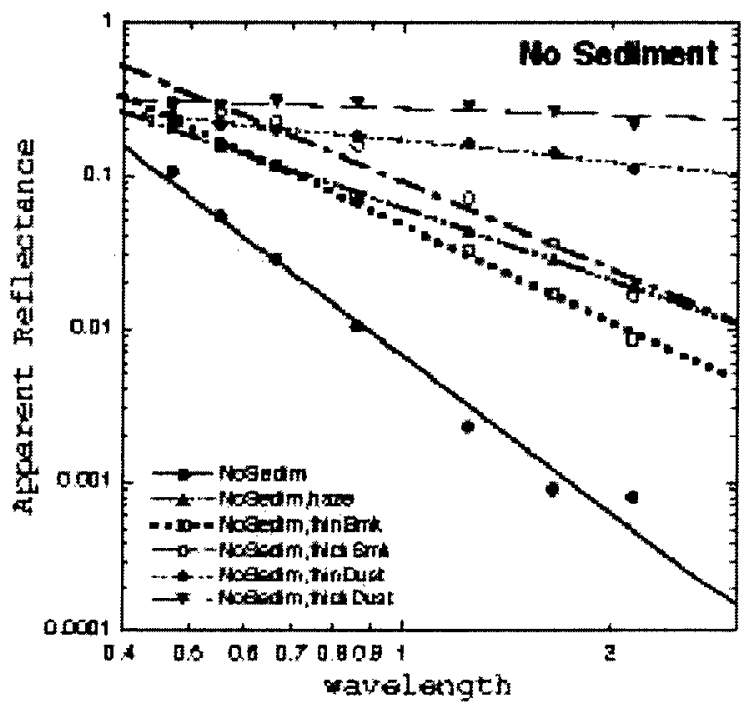

(b)

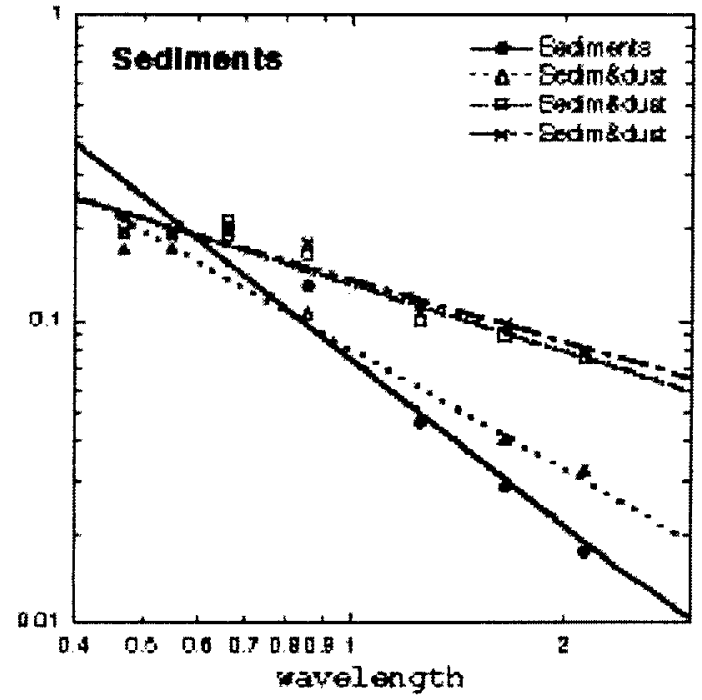

Fig. 5. (a): the wavelength dependences of MODIS data measured over clear waters and under different atmospheric conditions, such as those with heavy haze, light and heavy smoke, light and heavy dust; and (b): similar to (a) but for MODIS data acquired over ocean areas with sediments and under varying atmospheric dust concentrations.

We have analyzed more than 30 MODIS data sets acquired over different geographical locations and under varying atmospheric conditions from very clear to heavy smoke or heavy dust. Figure 6 shows results for the $0.55-\mu \mathrm{m}$ channel reflectance differences, $\Delta \rho(0.55 \mu \mathrm{m})$, for many clear water areas and turbid water areas having large amounts of sediments. Most of the clear water areas (open circle) have $\Delta \rho(0.55 \mu \mathrm{m})$ of 0.01 or less, while most of the turbid water areas (filled triangle) greater than 0.01 . There are only a few exceptions. For examples, some of clear water areas with heavy smokes or heavy dusts have $\Delta \rho(0.55 \mu \mathrm{m})$ values greater than 0.01 . These areas 
would be classified as sediment areas based only on the $\Delta \rho(0.55 \mu \mathrm{m})$ threshold value selected above. In order to avoid this type of mis-classifications, we have developed another threshold to de-select these heavy dust or heavy smoke areas. If $\rho(0.47 \mu \mathrm{m})>0.25$, heavy dust or heavy smoke are possible and the area will not be considered as sediment area. After applying the two thresholds to each pixel in MODIS images, the resulting masks appear to be quite reasonable.

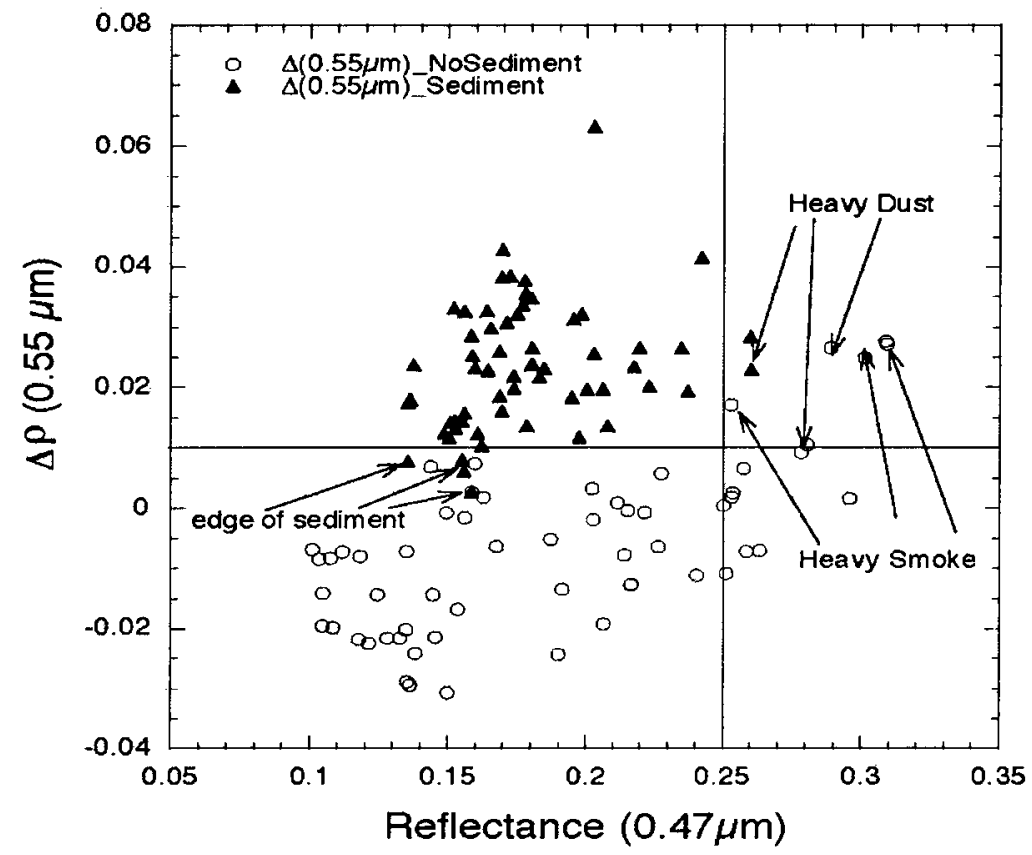

Fig. 6. The $0.55-\mu \mathrm{m}$ channel reflectance differences for many clear water areas and turbid water areas having large amounts of sediments. The heavy smoke and heavy dust pixels above the 0.01 threshold value were re-classified as non-sediment pixels based on their high reflectance values at $0.47 \mu \mathrm{m}$.

\section{Sample Results}

The empirical algorithm described above has been applied to numerous MODIS data sets. Sample results from the data acquired over the west coast of Africa, Arabian Sea, Mississippi Delta, west coast of Florida, northern Africa, and southeastern Australia are described below. The color images in the left panel of Figures $6-11$ are all processed from the MODIS channels at 0.66 $\mu \mathrm{m}$ (red), $0.55 \mu \mathrm{m}$ (green), and $0.47 \mu \mathrm{m}$ (blue). The black and white images in the right panel of Figures 6-11 are sediment/bottom mask images derived from the MODIS data sets using our algorithm.

\subsection{Western Africa}

The left panel of Figure 7 shows a MODIS image acquired on January 7, 2002 over the west coastal areas of Africa. The image covers roughly the latitude range of $11^{\circ} \mathrm{N}-16^{\circ} \mathrm{N}$ and the longitude range of $10^{\circ} \mathrm{W}-18^{\circ} \mathrm{W}$. The left portion of the image is the Atlantic Ocean. The upper middle and right portions are desert areas. The lower middle and right portions are tropical areas. The right panel of Figure 7 shows our sediment mask image. Narrow stripes over the coastal 
waters and rivers are picked out. Large areas with significant amount of sediments from a river discharge near the bottom part of the image are also well identified.

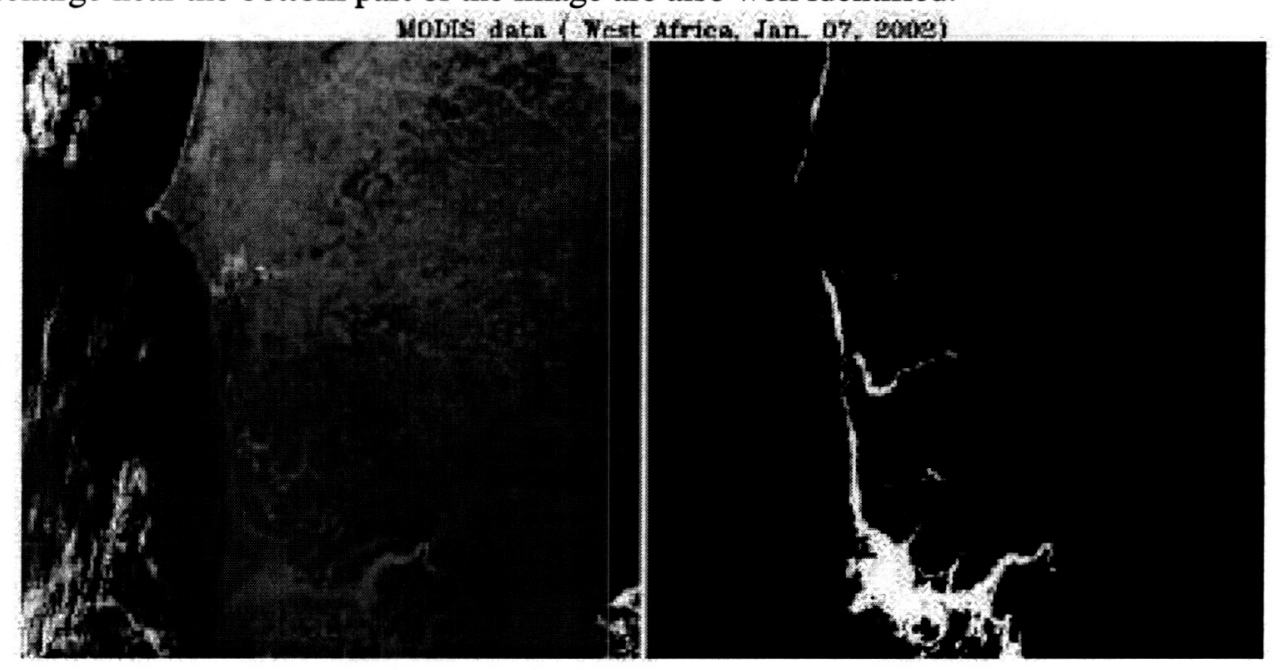

Fig. 7. Left panel: MODIS color image (red: $0.66 \mu \mathrm{m}$; green: $0.55 \mu \mathrm{m}$; blue: $0.47 \mu \mathrm{m}$ ) acquired on January 7, 2002 over the west coastal areas of Africa; Right panel: the corresponding sediment and shallow water mask image.

\subsection{Arabian Sea}

The left panel of Figure 8 shows a color image processed from the MODIS data collected over the Arabian Sea and nearby areas on October 28, 2001. The image covers approximately the latitude range of $20^{\circ} \mathrm{N}-25^{\circ} \mathrm{N}$ and the longitude range of $65^{\circ} \mathrm{E}-73^{\circ} \mathrm{E}$. The Gulf of Kutch is seen in the middle portion of this image. The City of Karachi in Pakistan is located near the tip in the upper left portion of the image. The right panel of Figure 8 shows the sediment mask image. Our masking algorithm has successively picked up turbid water areas seen in the left panel image.
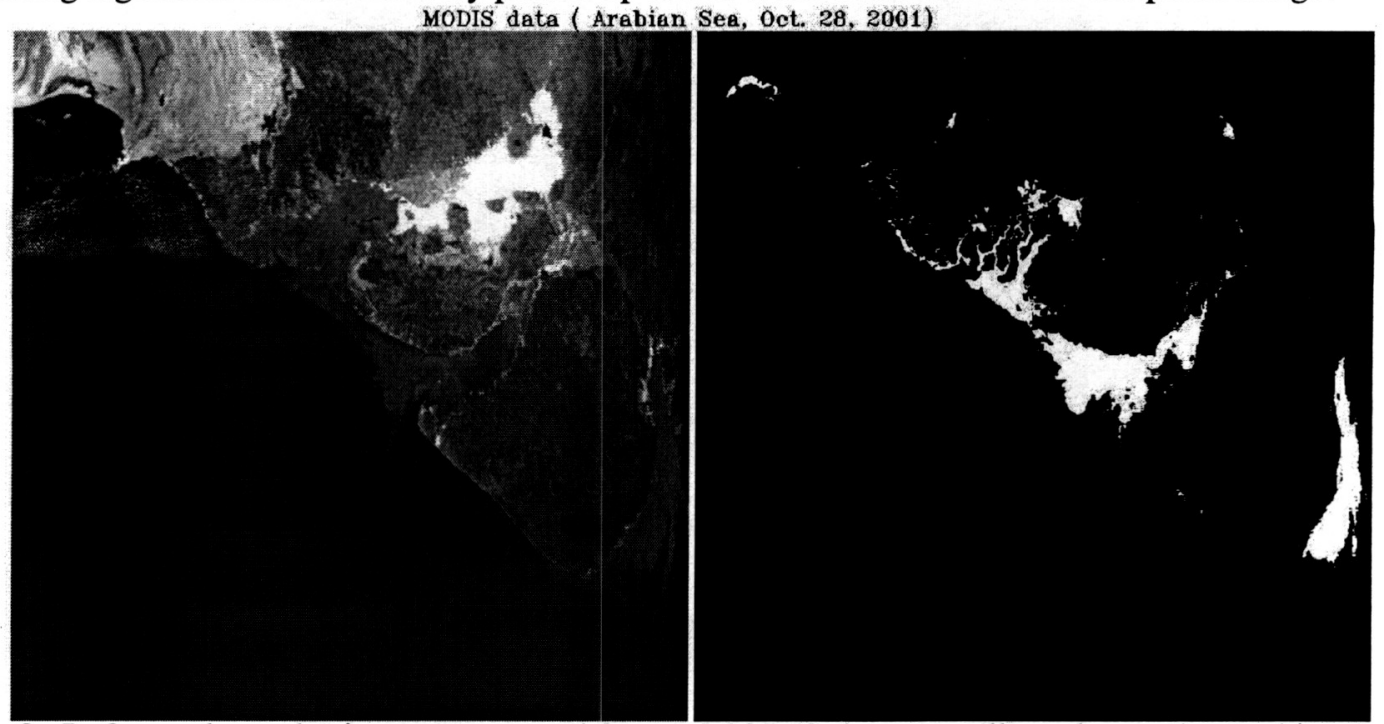

Fig. 8. Left panel: a color image processed from a MODIS data set collected over the Arabian Sea and nearby areas on October 28, 2001; Right panel: the corresponding sediment and shallow water mask image 


\subsection{Mississippi Delta}

The left panel of Figure 9 shows a color image processed from the MODIS data measured over the Southern part of US and the Gulf of Mexico on March 5, 2001. The image covers approximately the latitude range of $28^{\circ} \mathrm{N}-31^{\circ} \mathrm{N}$ and the longitude range of $87^{\circ} \mathrm{W}-94^{\circ} \mathrm{W}$. The right panel of Figure 9 shows the sediment mask image. The large bluish and brownish water areas in the left panel image are properly masked as sediment areas in the right panel image. For examples, the areas near the Mississippi river discharge region in the lower right portion of the left panel image are masked as sediment areas in the right panel. Mobile Bay, its outflow plume and the adjacent sound near the upper right corner of the left panel image are also masked as high sediment areas.

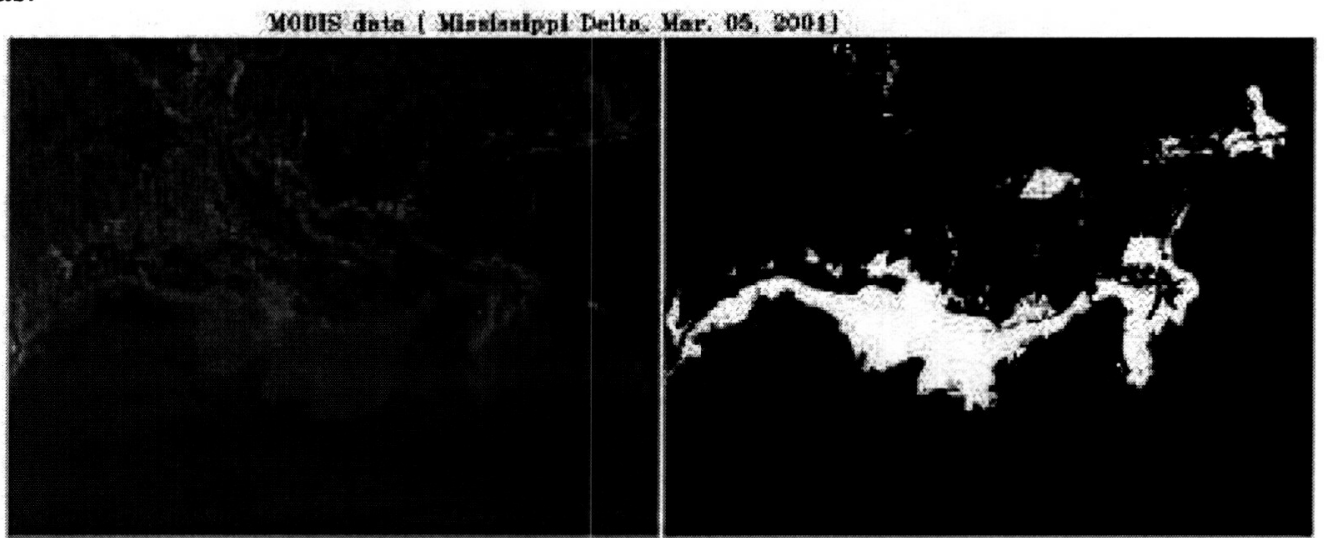

Fig. 9. Left panel: a color image processed from a MODIS data set measured over the southern part of US and the Gulf of Mexico on March 5, 2001; Right panel: the corresponding sediment and shallow water mask image.

\subsection{West Coast of Florida}

The left panel of Figure 10 shows a color image processed from the MODIS data measured over the southeastern part of US on March 7,2001. The image covers roughly the latitude range of $24^{\circ} \mathrm{N}-30^{\circ} \mathrm{N}$ and the longitude range of $80^{\circ} \mathrm{W}-85^{\circ} \mathrm{W}$. The right panel of Figure 10 shows the sediment/bottom mask image. Large portions of shallow water areas with measurable bottom reflections along the west coast of Florida are picked in the masking image.

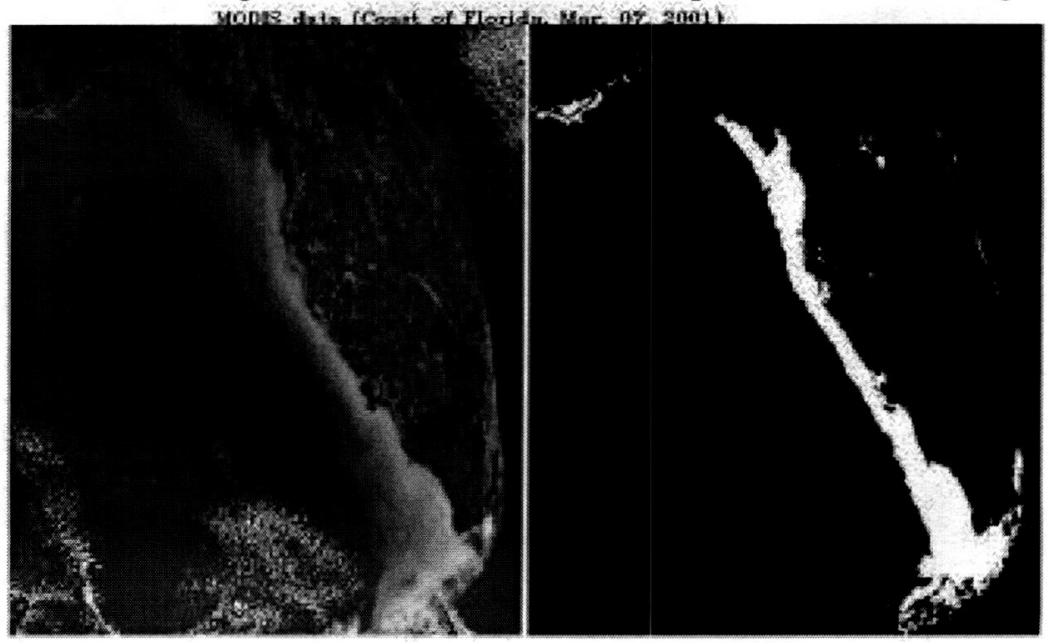


Fig. 10. Left panel: a color image processed from a MODIS data set collected over the Eastern Gulf of Mexico on March 7, 2001: Right panel: the corresponding sediment and shallow water mask image.

\subsection{Africa Dust}

In order to demonstrate that our algorithm works well under heavy dusty conditions, we show a color image in the left panel of Figure 11, which is processed from the MODIS data collected over northwestern part of Africa on January 7, 2002. It covers roughly the latitude range of $24^{\circ} \mathrm{N}-29^{\circ} \mathrm{N}$ and the longitude range of $10^{\circ} \mathrm{W}-16^{\circ} \mathrm{W}$. Dust plumes blowing off the Saharan Desert are evident in this image. The right panel of Figure 11 shows the sediment mask image. Water areas covered by heavy dusts in the left panel image are not mistakenly classified as sediments in the right panel image. This shows that our algorithm works properly under the dusty condition.

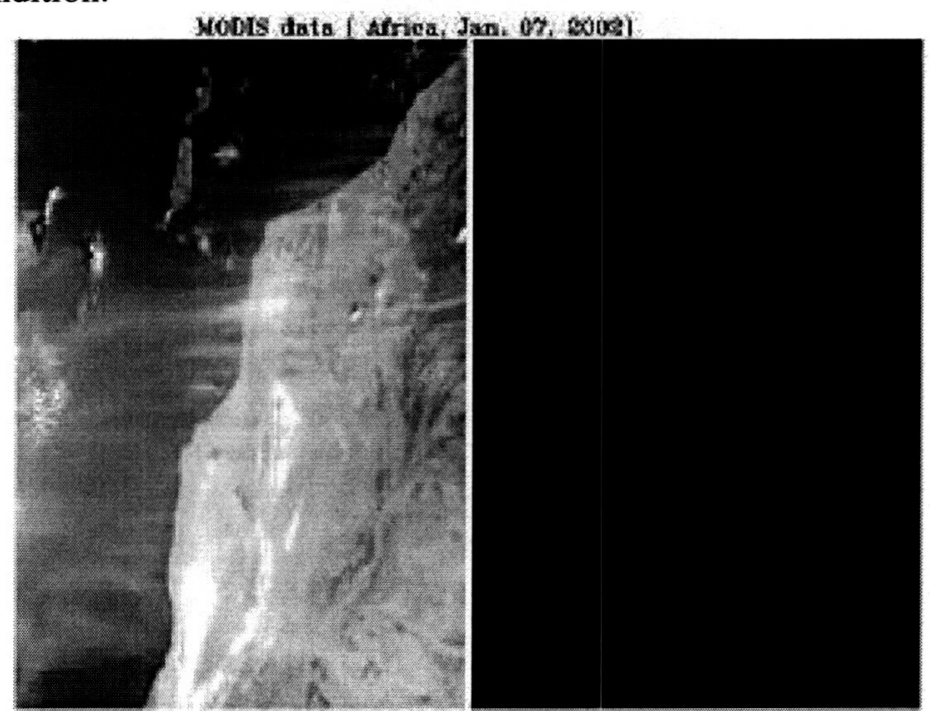

Fig. 11. Left panel: a color image processed from a MODIS data set collected over the northwestern part of Africa on January 7, 2002; Right panel: the corresponding sediment and shallow water mask image.

\subsection{Australia Smoke}

In order to demonstrate our algorithm also works under the heavy smoky conditions, we show another color image in the left panel of Figure 12, which is processed from the MODIS data collected over the southeastern part of Australia near Sydney on December 25, 2001. It covers roughly the latitude range of $30^{\circ} \mathrm{S}-38^{\circ} \mathrm{S}$ and the longitude range of $148^{\circ} \mathrm{E}-155^{\circ} \mathrm{E}$. Heavy smokes are easily seen in the left panel image over water surfaces. The right panel of Figure 12 shows the sediment mask image. Water areas covered by heavy smokes in the left panel image are not misclassified as sediments in the right panel image. This shows that our algorithm also works properly under the heavy smoke conditions. 


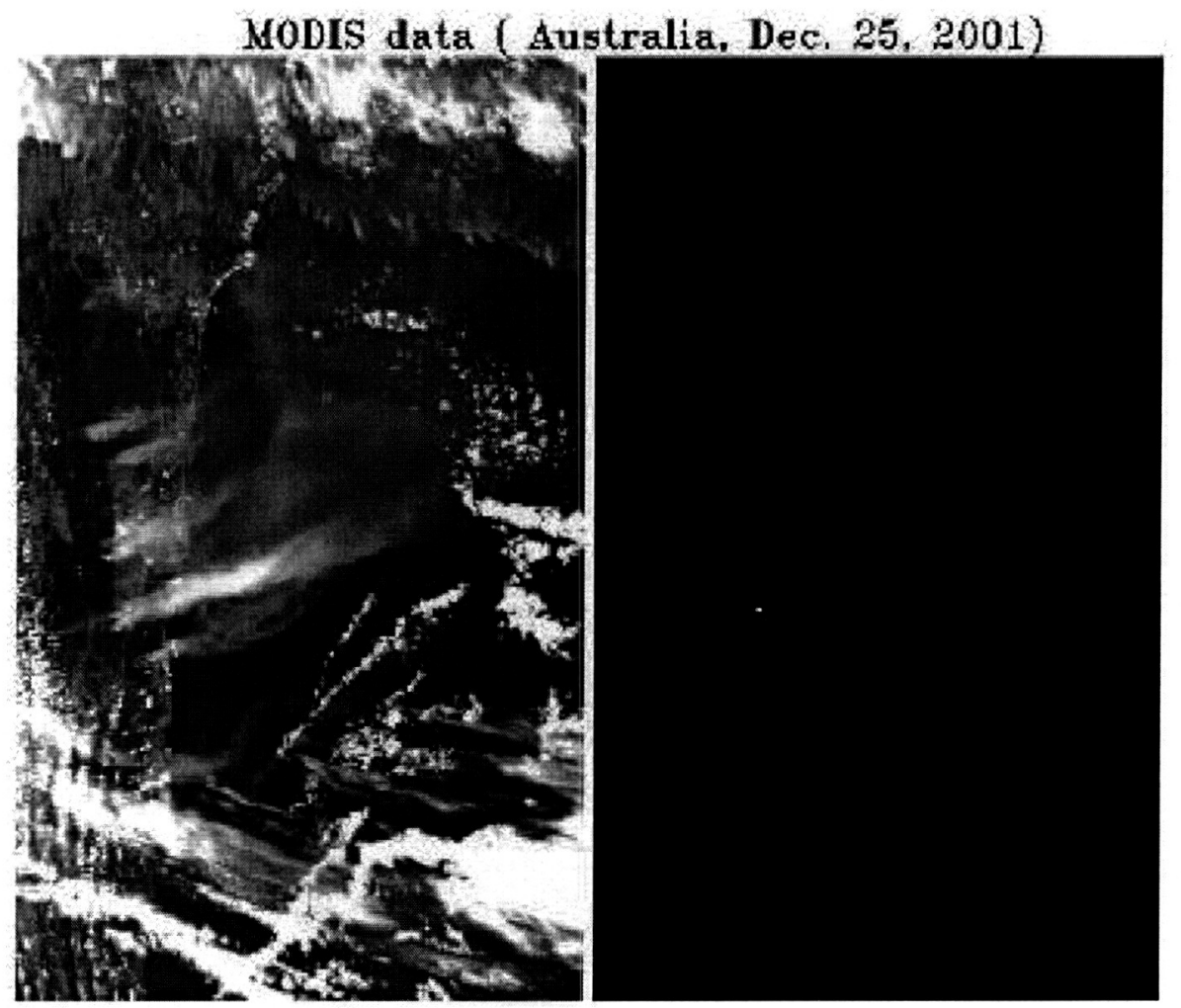

Fig. 12. Left panel: a color image processed from a MODIS data set collected over the southeastern part of Australia on December 25, 2001; Right panel: the corresponding sediment and shallow water mask image.

\section{Discussion}

Traditionally the detection of ocean color was done using only channels with wavelengths shorter than $0.86 \mu \mathrm{m}$ and mainly applied for remote sensing of case 1 water. Meanwhile, the MODIS channels at $1.2-2.1 \mu \mathrm{m}$ were found to be very useful for remote sensing of aerosol, in particular that of super micron dust and sea salt particles. These channels are located in a spectral region with strong liquid water absorption, and therefore can measure aerosol scattering independent of the turbidity of ocean waters and other properties. Using the special characteristics of these channels, an empirical algorithm for masking sediment and shallow water areas was developed. We have used three MODIS channels at longer wavelengths $(1.24,1.64$, and $2.13 \mu \mathrm{m})$ in addition to the $0.47-\mu \mathrm{m}$ channel to define a power-law baseline atmospheric reflection level. Sediments and shallow waters are masked as excess reflectance at $0.55-\mu \mathrm{m}$ above the power-law reflectance.

It should be pointed out that the MODIS instrument has a set of highly sensitive narrow channels designed specifically for remote sensing of the clear deep ocean waters and located in the wavelength range between 0.41 and $0.86 \mu \mathrm{m}$ (King et al., 1992; Gordon, 1997). Over the bright coastal waters, quite a few of these ocean color channels can be saturated because of too much radiance reaching the relevant detectors. To avoid this problem, we have used only the seven land and cloud channels for this algorithm. 
The algorithm described in this paper is mainly designed for masking out all bright pixels in coastal water areas so that these pixels will not be used during the retrievals of aerosol information from MODIS data. We mask out pixels with high sediment reflectances and shallow water pixels with detectable bottom reflections using the $0.55-\mu \mathrm{m}$ channel reflectance differences. During the study we noticed that it may be possible to develop more refined algorithms to separate sediment areas from shallow water areas using a combination of reflectance differences of the $0.55-\mu \mathrm{m}$, $0.66-\mu \mathrm{m}$, and $0.86-\mu \mathrm{m}$ channels, each with a different penetration depth (see Table 1 ). The $0.66-$ $\mu \mathrm{m}$ and $0.86-\mu \mathrm{m}$ channels receive little radiances resulted from the bottom reflection because of the increased liquid water absorption (Mobley, 1994). Unlike case 1 waters, case 2 waters are located in well defined geographical regions. The sources of sediments from river runoff are generally known. The spectral properties of these sediments can be measured during field experiments. It may be possible to develop further refined region-specific empirical algorithms for remote sensing of sediments and shallow waters from MODIS data.

\section{Summary}

In order to improve the MODIS operational aerosol retrieving algorithm, we have developed a simple and robust method using a set of MODIS land and cloud channels in the visible and near-IR spectral region for identifying coastal waters with significant amounts of suspended sediments and shallow waters with detectable bottom reflections. The method is developed based on the analyses of many MODIS data sets measured under different atmospheric conditions. Quite reasonable results have been obtained when the method is applied to full MODIS imaging data sets acquired over different geographical regions in the globe.

\section{Acknowledgement}

The authors are grateful to Wayne Essais of NASA GSFC for useful discussions. This research was supported by the NASA Goddard Space Flight Center and the Office of Naval Research.

\section{References}

Eck, T. F., B. N. Holben, O. Dubovik, A. Smirnov, I. Slutsker, J. M. Lobert, and V. Ramanathan, Column-integrated aerosol optical properties over the Maldives during the northeast monsoon for 1998-2000, J. Geophys. Res., 106, 28555-28566, 2001.

Gordon, H. R., D. K. Clark, J. L. Mueller, and W. A. Hovis, Phytoplankton pigments derived from the Nimbus-7 CZCS: initial comparisons with surface measurements, Science, 210, 6366, 1980.

Gordon, H. R., Atmospheric correction of ocean color imagery in the Earth Observing System era, Journal of Geophysical Research, 102, 17081-17106, 1997.

Hooker, S. B., W. E. Esaias, G. C. Feldman, W. W. Gregg, and C. R. McClain, SeaWiFS Technical Report Series: Volume 1, An overview of SeaWiFS and ocean color, NASA, Greenbelt, MD, Technical Memorandum 104566, July 1992.

Hovis, W. A., D. K. Clark, F. Anderson, R. W. Austin, W. H. Wilson, E. T. Baker, D. Hall, H. R. Gordon, J. L. Mueller, S. Y. E. Sayed, B. Strum, R. C. Wrigley, and C. S. Yentsch, Nimbus 7 coastal zone color scanner: system description and initial imagery, Science, 210, 60-63, 1980.

Justice, C., Vermote, E., Townshend, J. R. G., Defries, R., Roy, D. P., Hall, D. K., Salomonson, V. V., Privette, J., Riggs, G., Strahler, A., Lucht, W., Myneni, R., Knjazihhin, Y., Running, S., Nemani, R., Wan, Z., Huete, A., van Leeuwen, W., Wolfe, R., Giglio, L., Muller, J-P., Lewis, P., \& Barnsley, M. (1998), The Moderate Resolution Imaging Spectroradiometer (MODIS): Land remote sensing for global change research, IEEE Trans. on Geosci. Remote Sensing, 36, 1228-1249, 1998. 
King, M. D., Y. J. Kaufman, W. P. Menzel, and D. Tanre, Remote sensing of cloud, aerosol and water vapor properties from the Moderate Resolution Imaging Spectrometer (MODIS), IEEE Trans. Geosci. Remote Sens., 30, 2-27, 1992.

Mobley, C. D., Light and Water Radiative Transfer in Natural Waters, Academic Press, 80-100, 1994.

Morel, A., and L. Pirieur, Analysis of variations in ocean color, Limnol. Oceanogr., 22, 709-722, 1977.

Remer, L. A., Tanré, D., Kaufman, Y. J., Ichoku, C., Mattoo, S., Levy, R., Chu, D.A., Holben,B.N., Dubovik,O., Smirnov,A., Martins,J.V., Li, R-R., Ahmad,Z., Validation of MODIS Aerosol Retrieval Over Ocean, Geophys. Research Letter, In press.

Salomonson, V. V., W. L. Barnes, P. W. Maymon, H.E. Montgomery, and H. Ostrow, 1989, MODIS: Advanced facility instrument for studies of the earth as a system, IEEE Trans. Geosci. Remote Sens., 27, 145-153.

Tanré D., Kaufman, Y. J., Herman, M., \& Mattoo, S., Remote sensing of aerosol properties over oceans using the MODIS/EOS spectral radiances, Journal of Geophysical ResearchAtmospheres, 102(D14), 16971-16988, 1997.

Vane, G., R. O. Green, T. G. Chrien, H. T. Enmark, E. G. Hansen, and W. M. Porter, The Airborne Visible/Infrared Imaging Spectrometer, Remote Sens. Env., 44, 127-143, 1993.

Wieliczka, D. M., S.-S. Weng, and M. R. Querry, Wedge shaped cell for highly absorbent liquids: infrared optical constants of water, Appl. Opt., 28, 1714-1719, 1989.

\section{List of Figures}

Fig. 1. Examples of apparent reflectance spectra acquired with the Airborne Visible Infrared Imaging Spectrometer (AVIRIS) from a NASA ER-2 aircraft at an altitude of $20 \mathrm{~km}$ over the very turbid water (solid line) and relatively clearer water (dotted line). The AVIRIS data were measured over water surfaces close to the Honolulu Airport in April 2000.

Fig. 2. MODIS image (red: $0.66 \mu \mathrm{m}$; green: $0.55 \mu \mathrm{m}$; blue: $0.47 \mu \mathrm{m}$ ) acquired over the east coastal areas of China on November 11, 2001. The image shows low sediment areas (\#15), high sediment areas (\#6-10) and varying amount of pollution aerosol - the gray-brown haze.

Fig. 3. (a): Plot of the apparent reflectance (reflectance of the ocean + atmosphere) as a function of wavelength for clear water (areas 4 and 5, marked in Fig. 2); and (b): a similar plot but for the turbid water areas 8 and 9, as marked in Fig. 2 . The line in (b) was obtained using the area 9 data points from the $0.47-, 1.24-, 1.64-$ and $2.13-\mu \mathrm{m}$ channels.

Fig. 4. Reflectance differences for the 0.47-, 0.55- 0.66- and 2.13- $\mu$ m channels for all the 10 selected targets marked in Fig. 2 . The reflectance difference is calculated as the difference between the actual reflectance measured at the top of the atmosphere and the power law interpolated reflectance (linear fit in a $\log x \log$ scale). The line at 0.01 is the threshold value used to identify the pixels with high sediment reflectance for masking.

Fig. 5. (a): the wavelength dependences of MODIS data measured over clear waters and under different atmospheric conditions, such as those with heavy haze, light and heavy smoke, light and heavy dust; and (b): similar to (a) but for MODIS data acquired over ocean areas with sediments and under varying atmospheric dust concentrations.

Fig. 6 . The $0.55-\mu \mathrm{m}$ channel reflectance differences for many clear water areas and turbid water areas having large amounts of sediments. The heavy smoke and heavy dust pixels above 
the 0.01 threshold value were re-classified as non-sediment pixels based on their high reflectance values at $0.47 \mu \mathrm{m}$.

Fig. 7. Left panel: MODIS color image (red: $0.66 \mu \mathrm{m}$; green: $0.55 \mu \mathrm{m}$; blue: $0.47 \mu \mathrm{m}$ ) acquired on January 7, 2002 over the west coastal areas of Africa; Right panel: the corresponding sediment and shallow water mask image.

Fig. 8. Left panel: a color image processed from a MODIS data set collected over the Arabian Sea and nearby areas on October 28, 2001; Right panel: the corresponding sediment and shallow water mask image.

Fig. 9. Left panel: a color image processed from a MODIS data set measured over the southern part of US and the Gulf of Mexico on March 5, 2001; Right panel: the corresponding sediment and shallow water mask image.

Fig. 10. Left panel: a color image processed from a MODIS data set collected over the southeastern part of US on March 7, 2001: Right panel: the corresponding sediment and shallow water mask image

Fig. 11. Left panel: a color image processed from a MODIS data set collected over the northwestern part of Africa on January 7, 2002; Right panel: the corresponding sediment and shallow water mask image.

Fig. 12. Left panel: a color image processed from a MODIS data set collected over the southeastern part of Australia on December 25, 2001; Right panel: the corresponding sediment and shallow water mask image. 
Submitted to IEEE: TGRS-00230-2002

\title{
Remote Sensing of Suspended Sediments and Shallow Coastal Waters
}

\author{
Rong-Rong Li, Yoram J. Kaufman, Bo-Cai Gao, and Curtiss $O$. \\ Davis
}

Popular Summary

Sediments in coastal waters are important for a variety of science disciplines. They indicate erosion in the coastal land regions. Since they reflect sunlight, they introduce errors into remote sensing of the water properties and the properties of the atmosphere. We encounter the problem in our method for observing global aerosol, mainly the dust and pollution emerging from East Asia and crossing the Pacific Ocean to the Americas. In this paper we show that data from the MODIS instrument on the Terra satellite can be used very effectively to derive the presence of sediments. This is possible since the sediments reflect the visible light but not the invisible light. MODIS data acquired over the east coast of China, west coast of Africa, Arabian Sea, Mississippi Delta, and west coast of Florida are used to demonstrate this method. 